\title{
Shear Behavior of Fiber Reinforced Concrete Beams Reinforced with Basalt FRP Bars
}

\author{
Abathar Al-Hamrani ${ }^{1}$, Wael Alnahhal ${ }^{1}$, Nasser Alnuaimi ${ }^{1}$
}

\begin{abstract}
This paper is focusing mainly on studying the shear behavior of basalt fiber reinforced concrete (BFRC) beams reinforced with basalt (BFRP) bars. Reinforced concrete beams reinforced with basalt bars were tested under shear loading test until failure. The beams were reinforced with sand coated BFRP bars as a flexural reinforcement, in addition to the discrete basalt macro-fibers, which were added to the concrete mix at two different volume fractions namely, $0.75 \%$, and $1.5 \%$. Two mixes with the aforementioned volume fractions were prepared and cured for 28 days before testing. The main parameters were the reinforcement ratio, the span to depth ratio and the volume fraction of discrete basalt minibars. Test Results showed a significant increase in the shear strength as the reinforcement ratio increases. In addition, using lower span to depth ratio resulted in an increase in the shear capacity. It has also revealed that using higher percentages of discrete basalt fibers enhanced the shear capacity, reduced the beam deflection, reduced the cracks width and propagation, and improved the beam ductility before failure.
\end{abstract}

Keywords - Shear behavior, Basalt bars, Basalt macro-fibers, Beam ductility.

\section{Introduction}

Qatar suffers from a harsh environment in the form of high temperature that prevails almost all year round in addition to severe humidity and coastal conditions. This exposure leads to the rapid deterioration and the reduction of the lifespan of reinforced concrete $(\mathrm{RC})$ infrastructure. The full functionality and safe use of the infrastructure in such environments can only be maintained by holistic approaches including the use of advanced materials for new construction. With the developments in materials science, the advanced composites, especially fiber reinforced polymer (FRP) materials are becoming viable alternatives to the traditional construction materials. Having superior durability against corrosion, versatility for easy in-situ applications and enhanced weightto-

strength ratios compared to their counterpart conventional materials, FRPs are promising to be the future of construction materials.

\footnotetext{
1 Department of Civil and Architectural Engineering, Qatar University, Qatar.
}

Although there is no particular limit for their shape, FRPs are mostly used for reinforcing the structural members instead of steel reinforcement in Civil Engineering applications. Glass FRP (GFRP) is normally the one currently used in Civil Engineering applications. More recently, FRP composites made

of basalt FRP (BFRP) have been introduced as an alternative to traditional steel reinforcement at a price comparable to glass fibers of about $\$ 2.5-5.0$ per $\mathrm{kg}$ [1], which is significantly lower than carbon fibers. BFRP bars are characterized by their corrosion resistance, greater strain at failure than carbon fibers, and better chemical resistant than glass fibers, particularly in a strongly alkaline environment [2-6]. A number of guidelines provide guidance on design and construction of structural concrete reinforced with glass, aramid and carbon FRP bars available in USA, Canada, and Japan [7-10]. These documents, however, do not provide specific provisions for structural concrete reinforced with BFRP bars.

It has been established that shear capacity of concrete is strongly dependent on the dowel action in the main reinforcement where the transverse rigidity of the main reinforcement significantly contributes to the dowel action [11]. A number of research studies investigated the concrete shear capacity in beams reinforced with GFRP Bars [11-15]. However, few studies were completed for beams with BFRP bars. Ovitigala and Issa [16] concluded that the increase of the area of main reinforcement of beams reinforced with BFRP bars will increase the shear capacity of the tested beams. As well, Tomlinson and Fam [17] stated that increasing the reinforcement ratio of the longitudinal reinforcement of beams reinforced with BFRP bars from 0.0039 to 0.0084 increased the shear strength by 54 percent.

Knowing that FRP bars are anisotropic materials with weaker strength in the transverse direction compared with the longitudinal direction, and having a relatively low modulus of elasticity compared with steel reinforcement, it is important to investigate the concrete contribution to shear strength for beams reinforced with BFRP bars. In addition, due to the elastic performance of the FRP reinforcing bars compared with steel bars, FRP bars fail in a brittle manner. Moreover, concrete itself is a brittle material. Previous investigations have shown that using discrete fibers in concrete increases its ductility due to the large compressive strains exhibited at failure [18]. Therefore, basalt macro-fibers is proposed in this study. Previous research studies demonstrated that the shear 
strength of RC members is significantly improved by adding an adequate quantity of steel or synthetic fibers [19-21].

This study will investigate the effect of volume fraction of basalt fibers on the shear performance of concrete beams reinforced with BFRP bars.

\section{The Experimental Program}

The experimental program comprises two parts: the first part aims at investigating the mechanical properties of BFR concrete in terms of compressive and flexural strengths. The second part aims at investigating the shear behavior of BFRC beams under four-point loading test.

\section{A. Mix Ingredients and Materials}

An ordinary Portland cement type 1 was used in the mix. The washed sand was used as the fine aggregates, while Gabbro aggregates were used as the coarse aggregates with a maximum size of $20 \mathrm{~mm}$. The water/cement ratio of the mix was 0.34 . The target strength of concrete was $50 \mathrm{MPa}$. Two different volume fractions of basalt fibers namely $0.75 \%$, and $1.5 \%$ by volume were added. The basalt fibers can be shown in Fig. 1 .

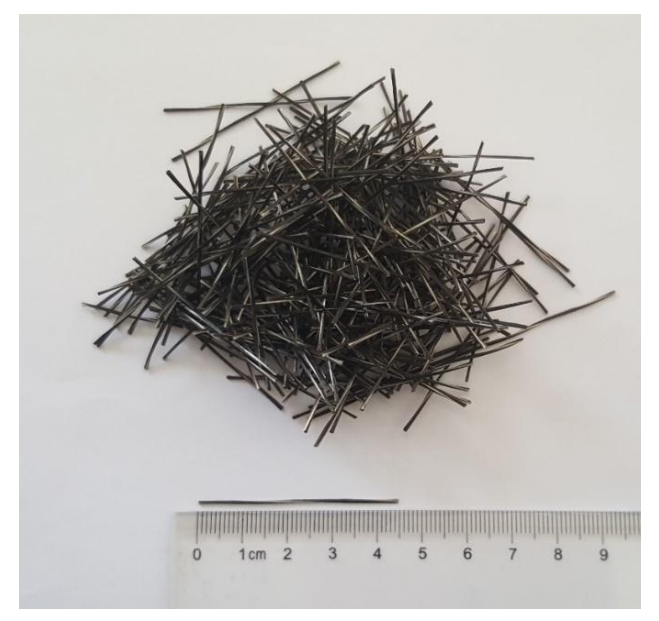

Figure 1: The discrete basalt fibers

\section{B. Flexural and Compression Tests}

The flexural and compression tests were conducted in accordance with ASTM C1609 and ASTM C39. For the flexural test, prisms with a size of $100 \mathrm{~mm} \times 100 \mathrm{~mm} \times 500$ $\mathrm{mm}$ were tested, and the average of five specimens for each mix was selected. For the compressive test 5 cylinders from each mix with a dimension of $150 \mathrm{~mm} \times 300 \mathrm{~mm}$ were tested then the average compressive strength was selected. All specimens were cured for 28 days and tested thereafter.

\section{Large-Scale Beams Shear Tests}

To study the shear behavior of BFRC beams, test was carried on large-scale beams with a size of $152 \mathrm{~mm} \times 254 \mathrm{~mm}$ $\times 2000 \mathrm{~mm}$ that were loaded until failure under four-point loads. Test set-up is shown in Fig.2. The beams were reinforced with different reinforcement ratios of sand coated basalt bars as a flexural reinforcement.

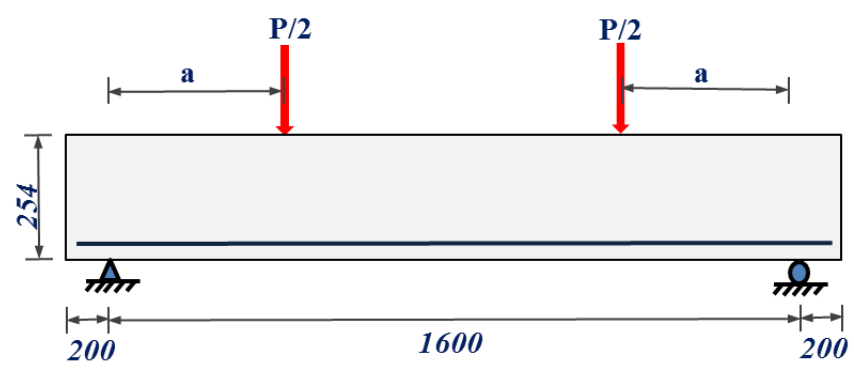

Figure 2: Large-Scale Beam Layout (Dimensions in mm)

\section{Tests Results and Discussion}

\section{A. Compressive Test Results}

The measured compressive strengths of the two concrete mixes are shown in Table 1 . The test results revealed that the addition of fibers has only a marginal effect on the compressive strength, where the concrete specimens with $1.5 \%$ volume fraction of basalt fibers experienced an increase of $9.4 \%$ in comparison to the concrete specimens with $0.75 \%$ volume fraction. However, the fibers addition has significantly improved the mode of failure from an explosive and brittle type of failure into a ductile failure. The FRC specimens keep sustaining load even after the occurrence of significant cracking and remain coherent and intact after failure. This behavior can indicate the advantages of fibers in inhibiting the brittle nature of concrete and maintaining the integrity of a structural element even after failure.

TABLE I: Average Compressive Strength and Flexural Tensile Strength Test Results

\begin{tabular}{|c|c|c|c|c|c|}
\hline $\begin{array}{c}\text { Fiber } \\
\text { Volume } \\
\text { Fraction } \\
(\%)\end{array}$ & $\begin{array}{c}\text { Sample } \\
\text { No. }\end{array}$ & $\begin{array}{c}\text { Comp. } \\
\text { Strength } \\
\text { (MPa) }\end{array}$ & $\begin{array}{l}\text { Aver. } \\
\text { MPa }\end{array}$ & $\begin{array}{c}\text { Flexural } \\
\text { Strength } \\
\text { MPa }\end{array}$ & $\begin{array}{l}\text { Aver. } \\
\text { MPa }\end{array}$ \\
\hline \multirow{5}{*}{0.75} & 1 & 59.88 & \multirow{5}{*}{57.49} & 6.03 & \multirow{5}{*}{5.93} \\
\hline & 2 & 58.14 & & 6.36 & \\
\hline & 3 & 56.99 & & 5.76 & \\
\hline & 4 & 55.97 & & 5.46 & \\
\hline & 5 & 56.46 & & 6.02 & \\
\hline \multirow{2}{*}{1.5} & 1 & 63.38 & \multirow{2}{*}{63.47} & 6.51 & \multirow{2}{*}{7.14} \\
\hline & 2 & 60.76 & & 7.95 & \\
\hline
\end{tabular}




\begin{tabular}{|l|l|l|l|l|} 
& 3 & 69.85 & & 7.25 \\
\cline { 2 - 3 } & 4 & 67.65 & \multirow{4}{*}{} & 7.06 \\
\cline { 2 - 3 } & 5 & 55.71 & & 6.9 \\
\hline
\end{tabular}

\section{B. Flexural Test Results}

An obvious better performance was noticed for the specimens with a higher percentage of fibers, as shown in Table 1. In comparison to compression test results, the effect of fibers was more noticeable in the flexural test results. It can be clearly seen from the test results that the flexural strength was increased by $17 \%$ when volume fractions of $1.5 \%$ were added. It is known that when the plain concrete cracks, the tensile capacity of concrete falls to zero, therefore, this increase in the flexural strength can be attributed to the postcracking behavior of fibers that are bridging the cracks, and keeps carrying the load beyond the fracture point.

\section{Shear Test Results}

In this test, large-scale beams reinforced with BFRP bars as the main reinforcement were loaded under four-point loads until failure. The test results revealed that increasing the reinforcement ratio from 0.003 to 0.0068 increases the shear capacity by $34.5 \%$. This indicates that the shear strength is significantly affected by the dowel action of the main reinforcement. In addition, the test results demonstrated a decrease in the shear capacity when a higher span to depth ratio was used. This can be attributed to the increased moment arm that will increase the beam deflection and cracks, which as a result degraded the beam's stiffness and strength.

The load-deflection behavior of beams reinforced with FRP bars divided into two stages: pre-cracking and post-cracking stages. In terms of deflection behavior before cracking for BFRP beams, results have shown a linear relationship between the load and deflection until the occurrence of the first crack. However, this relationship no longer exists after cracks appeared, because, with small increments in the applied load, the deflection increased more due to the reduction in the stiffness of BFRP beams, which depends mainly on the reinforcement ratio. It was noticed that beams with higher reinforcement ratio experienced less reduction in the stiffness of beams and as a result a less deflection. BFRP beams witnessed a lot of curvature before failure due to the relatively low elastic modulus and as a consequence, this led to an increase in the deflection and crack openings.

Furthermore, using a higher percentage of fibers in the tested beam with $1.5 \%$ volume fraction showed an increase in the shear strength in comparison to its counterpart beam with $0.75 \%$ volume fraction. As well, adding the discrete basalt fibers had a noticeable effect on the beam ductility. It was noticed that increasing the fiber content allows the formulation of multiple cracks distributed along the shear span, which consequently delayed the development of major cracks that can cause brittle failure.

Additionally, a reduction in the cracks width and an improvement in the stiffness of the beams were observed when higher percentages of basalt macro-fibers were introduced. The most prominent contribution of fibers is its post-failure behavior in the FRC beam due to the arresting mechanism of fibers that are bridging the cracks in concrete and keeps carrying the load beyond the fracture point of concrete, which resulted in a higher shear capacity. The aforementioned effects resulted from using higher percentages of fibers can be depicted from Figure 3, which illustrates the relation between the load and the displacement at the beam's midspan for two similar beams with two different volume fractions of basalt macro-fibers.

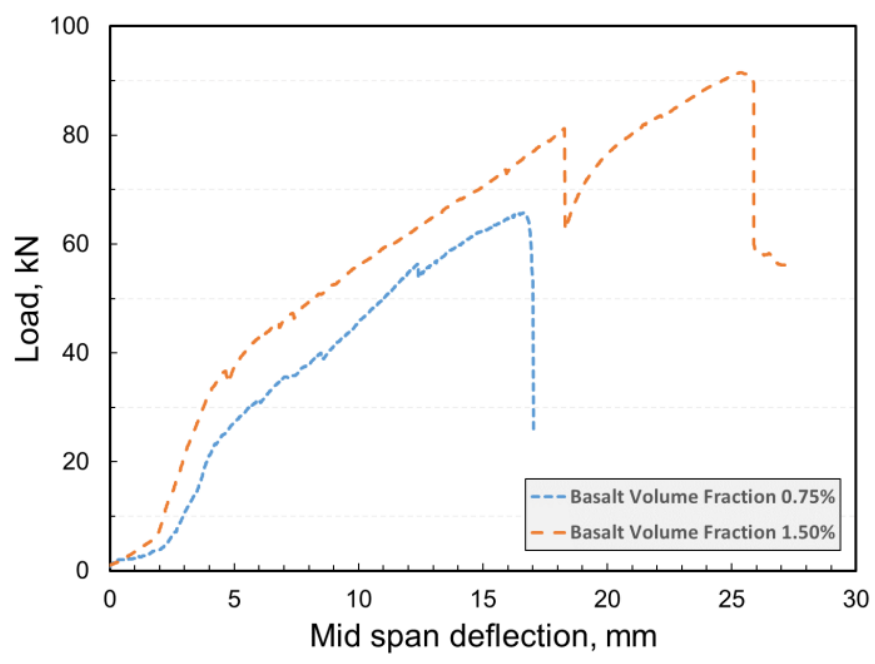

Figure 3: Load vs midspan deflection

\section{Conclusion}

In conclusion, this paper has investigated the mechanical properties of BFRC, and the shear behavior of FRC beams reinforced with basalt bars and discrete basalt minibars at different percentages. Our work led us to the conclusion that:

- Using a higher percentage of discrete fibers has only a marginal effect on the compressive strength. However, the type of failure was altered from explosive to ductile failure.

- The effect of fibers on the flexural strength was more pronounced than that on the compressive strength, due to the presence of the fibers that were bridging the concrete cracks and increasing the flexural strength capacity consequently.

- The dowel action of the main reinforcement has the most significant effect on enhancing the shear strength capacity of BFRC beams.

- Using larger shear spans will result in a higher midspan deflection and wider cracks, which will reduce the beam stiffness. 
- Increasing the volume fraction of the basalt macrofiber resulted in an improvement in the Shear strength capacity of the tested beams.

\section{Acknowledgment}

The authors show their gratitude to Qatar University for their financial support through the GCC joint research grant no. GCC-2017-008.

\section{References}

[1] Kameny Vek. (2010). "Advanced basalt fiber." (http://www.basfiber.com).

[2] Fahmy, M., Wu, Z., and Wu, G. (2009). "Seismic performance assessment of damage-controlled FRP-Retrofitted RC bridge columns using residual deformations." J. Compos. Constr., 10.1061/(ASCE)CC.1943-5614.0000046, 498-513.

[3] Erlendsson, J. O. (2012). "Continuous basalt fiber as reinforcement material in polyester resin." M.S. thesis, School of Science and Engineering at Reykjavík Univ., Reykjavík, Iceland.

[4] Sim, J., Park, C., and Moon, D. J. (2005). "Characteristic of basalt fiber as a strengthening material for concrete structures." Compos. Part B, 36(6), 504-512

[5] Van de Velde, K., Kiekens, P., Van Langenhove, L., Cater, S., (2002). Basalt fibers as reinforcement for composites, Editorial, International Composites News, March 2002.

[6] El Refai, A., Ammar, M., and Masmoudi, R. (2014). "Bond performance of basalt fiber-reinforced polymer bars to concrete. J. Compos. Constr. Vol. 6-80.

[7] ACI (American Concrete Institute). (2015). "Guide for the design and construction of structural concrete reinforced with FRP bars." ACI 440.1R-15, Farmington Hills, MI

[8] ISIS Canada, Reinforcing Concrete Structures with Fiber Reinforced Polymers. Design Manual N8 3 Version 2, Canada ISIS Canada Corporation, Manitoba, 2007.

[9] CSA, S806-12: Design and Construction of Building Components with Fiber-Reinforced Polymers, Canadian Standards Association, Canada, 2012.

[10] Japan Society of Civil Engineers (1997). Recommendation for design and construction of concrete structures using continuous fiber reinforcing materials. Concrete Engineering Series 23; Tokyo, Japan Society of Civil Engineers.

[11] Razaqpur, A. G., Isgor, B. O., Greenaway, S., and Selley, A. (2004). "Concrete contribution to the shear resistance of fiber reinforced polymer reinforced concrete members." J. Compos. Constr., Vol. 8:5, 452-460.

[12] Yost, J. R, Gross, S. P, and Dinehart, D. W. (2001). "Shear strength of normal strength concrete beams reinforced with deformed GFRP bars." J. Compos. Constr., Vol. 5:4, 268-275.

[13] Tureyen, A. K., and Frosch, R. J. (2002). "Shear tests of FRP-reinforced concrete beams without stirrups.” ACI Struct. J., 99(4), 427-434.

[14] Gross, S. P., Yost, J. R., Dinehart, D. W., Svensen, E., and Liu, N. (2003). "Shear strength of normal and high strength concrete beams reinforced with GFRP reinforcing bars." Proc., Int. Conf. on High Performance Materials in Bridges, ASCE, Kona, Hawaii, 426-437.

[15] El-Sayed, A. K., El-Salakawy, E., and Benmokrane, B. (2006b). "Shear strength of FRP-reinforced concrete without transverse reinforcement." ACI Struct. J., 103(2), 235-243.

[16] Ovitigala, T., and Issa, M. A. (2013b). "Shear behavior of concrete beams reinforced with basalt fiber reinforcement polymer (BFRP) bars." Proc., 11th Int. Symp. on FRP for Reinforced Concrete Structures, J. Barros and J. Sena-Cruz, eds., Guimaraes, Portugal.
[17] Tomlinson, D., and Fam, A. (2014). "Performance of concrete beams reinforced with basalt FRP for flexure and shear." J. Compos. Constr., 10.1061/(ASCE)CC.1943-5614.0000491, 04014036.

[18] K. Holschemacher, T. Mueller, and Y. Ribakov (2010). "Effect of steel fibers on mechanical properties of high-strength concrete," Materials and Design, 31(5), 2604-2615.

[19] Sahoo DR, Sharma A. Effect of steel fiber content on behavior of concrete beams with and without stirrups. ACI Struct J 2014;111(5):1157-66.

[20] El-dieb, A.S., El-maaddawy, T.A. \& Al-rawashdah, O., 2014. Shear behavior of ultra - high - strength steel fiber - reinforced self compacting concrete beams. , pp.972-979.

[21] Ding, Y., You, Z. \& Jalali, S., 2011. The composite effect of steel fibres and stirrups on the shear behaviour of beams using self-consolidating concrete. Engineering Structures, 33(1), pp.107-117. Available at: http://dx.doi.org/10.1016/j.engstruct.2010.09.023. 